\title{
VARIABLE STAR OBSERVING AND RESULTS FROM OBSERVATIONS MADE AT LOVEDALE, SOUTH AFRICA.
}

\author{
By A. W. ROBerts.
}

[READ 28TH OC'TOBER, 1891.]

Is the present day it would naturally seem that giant telescopes: and first class observatories, equipped regardless of expense and directed by men great among their fellows, have elbowed the humble. amateur out of the road.

This may be so in some walks of astronomical research, but it is not so in all. There are still pleasant ways for the possessor of nothing but a good pair of eyes and the determination to use them well to travel.

Of these by-ways-and there are many full of the promise of success to the assiduous student-one of the most interesting is the study of, and search after, variable stars.

It is pre-eminently a study for the amateur, using the word in: its generally received though wrong meaning. Every true asıronomer is an amateur of astronomy.

For one section of astronomical research powerful lenses in combination with the most exquisite workmanship in circles and screws. are needed. For the study of variable stars as well as of star colours, and stellar configurations, instrumental aid should only be used when absolutely necessary. And when it is necessary all larger glasses should be shunned, the best instrument for all stars above the 9th mag. being a binocular of good definition. Likewise no extensive and expensive library of catalogues, charts, proceedings, tables, reductions and other necessary adjuncts to more ambitious. work is needed.

A good atlas such as Proctor's, a reliable hand-book such as. Chambers', are all that is necessary, at least as a beginning. And what a splendid field for research there is among the southern stars!: The number of known Northern variables is nearly two hundred. The Southern variables as yet only number fifty. In Northern 
climes three clear nights in succession is a precious time for the observer, Here we have sometimes a clear run of twenty, thirty, and even forty cloudless nights. The advantage of this in the study of variable stars, and specially of short period variables, will at once, be seen. If sequences of a certain group of stars be taken say on ten consecutive nights there is the probability of detecting every short period variable in that zone. Also the Southern heavens possess two of the richest mines of future discovery: the region round $\theta$ Argus, and the "short period variable zone" which passes through Vela, Carina, Crux, Musca, Circinus, Triangulum and Norma. In this zone alone there are fifteen variables known or suspected. It is to this region that an observer seems instinctively to be drawn. The vast array of stars, the gauzy streamers from the Milky Way, intertwining with lines and wisps of stars, invite attack. But at the same time the very nature of the region to be observed demands that our attack shall be skilful in design and persistent in execution. When it was determined here to commence with the lower portions of this zone the "how" to do so was an important question.

After a period of trial the following method was adopted as one that would ultimately give the best results.

An ordinary sheet of drawing paper was taken, and the positions of all stars in the zone under examination-generally $5^{\circ}$ squarewere charted down. For example, one evening all the stars in an oblong formed by the four brightest stars in the Southern Cross were plotted down.

This was done as carefully as possible to ensure the correct identification of any particular star.

The choice of an instrument was not a serious difficulty. Some observers, perhaps the majority, prefer an opera glass, as it gives a wider field and less loss of light.

For my own part I found an ordinary theodolite quite as serviceable. It was steady, it was easily moved in altitude and azimuth, it left the hands free, and above all it diminished "twinkling," that foe of all observers, reducing it some evenings to a minimum. Stili, as has been said, the opera glass has given better results in the hands of competent observers than any other form of telescope. If it be mounted on an alt-azimuth stand its performance will be increased by giving the observer the use of his right hand for noting down results. To return to the method of charting. After all the stars; have been carefully plotted down, the next step is to fix upon certain 
stars as starting points from which to give relative magnitudes to all the other stars in the zone.

It is well to do this though it is not absnlutely necessary, as it gives a urity to all the observations and gives also the absolute magnitudes with reference to the whole heavens, and not the relative magnitudes with regard to the zone under consideration. Certain stars are therefore selected whose magnitudes differ by as nearly as possible half a magnitude. These stars are carefully compared with well known " fixed" stars. In Dr. Gould's " Uranometria Argentina" a list of standard stars is given.

The observer is now ready to deal with all the stars on his paper, generally between one and two hundred in zones in or near the Milky Way. The two brightest stars whose magnitudes have already been assigned are taken, and all stars between them are compared and values assigned. Thus suppose the brightest comparison star is 5. and the next 5.5. Any star very much nearer the brighter will be $5 \cdot 2$, and a star where the difference is almost imperceptible will he $5 \cdot 1$. This method of accepting values that have already been fixed by photometric measurement saves the observer all the trouble of deciding what quantity he will reckon equal to $\frac{1}{10}$ and what to $\frac{2}{10}$ As a rule, few observers can discern with absolute precision $\frac{1}{10}$ of a magnitude. The usual "step" from one intensity to another is about $\frac{1}{8}$ of a magnitude.

This means that when we notice that one star is just brighter thin another, but that is all, the difference between them is one step. A difference very small but yet distinct enough, is two steps; a difference quite marked, three steps.

Beyond this we need not go, as it is always possible to get two near stars separated by half a magnitude with which we can compare a star intermediate. The value of one step is constant for the same observer. My own determinations give a value a little less than $\frac{1}{9}$ of a magnitude After the stars between 5 and 5.5 have been valued the observer takes up those between 5.5 and 6.0 and so on down to the 9th magnitude. It is advisable always to go over the whole lot again by inter-comparison as a chance error will give a great deal of trouble.

With micrometer measurements a series of values will decide the worth of any single observation. Not so in variable star work.

If an error has been made it will take the observations of years to allay the suspicions aroused as to its variation.

The next evening the observations are again gone over in the 
same way on the same sheet, the values assigned being pliced alongside those of the previous evening.

The same is done on a third night, and also on a fourth. The thought will at once present itself, "will not the recorded magnitudes on the different nights become inextricably mixed." The first night I write down the figures with an ordinary black pencil, the second night with a blue pencil, the third night with black ink, and the fourth with red ink. When this has been done on four nights an exact fac-simile of the position of the stars is taken on a clean sheet of drawing paper by pressing the marks with the sharp point of a pencil or puncturing the paper with a pin.

With this new sheet another set of values may be obtained as before. After four or five sheets are obtained the observer may take up another zone, returning to the first one at the end of every month. This method is an exhaustive, perhaps also exhausting one; yet if carefully and systematically carried out it would result in the discovery of all variables above the 9 th magnitude. One objection to it is its tediousness. It will be in the memory of many that when a search was begun for the planet Neptune, the methods adopted by Prof. Challis and Dr. Galle were quite different. Prof. Challis carefully charted night after night all the stars in the region where Prof. Adams said the planet would be found, intending when he had leisure and a large number of observations to compare them.

This method was slow but sure. Neptune was in the observer's net, and only time and opportunity were needed to sort it out from the thousand and one other stars that had been charted down. The guiding idea, at least if Bremiker's charts had not been available in Dr. Galle's search was to look for a star "with a disc." His method was the more rapid, but it depended entirely upon the correctness of the data given. Prof. Pickering has suggested a somewhat similar method of search after short period variahles. It has been noticed that almost all short period variables are white, that they usually lie in that portion of the Milky Way h,etween XII and XVIII R.A., and that they generally have a small companion about $3^{\prime}$ of arc distant and with a position angle of $70^{\circ}$ reckoned from the soutb towards the east. It has been suggested, therefore, that observers should sweep along this region and when they come across any star fulfilling these conditions to watch it carefully for a time. While very short period variables are white, ordinary variables and especially long period variables are red. It has been asserted also that when 
a long period variable approaches a maximum its red colour becomes less intense, the remarkable variable $\mathrm{R}$ Carinæ being cited as an instance of this change.

If the increase of light be due to the increase of heat this is just what ve would expect.

A strange connection exists between the intensity of the minimum, the duration of minimum and the whole period of variation, especially with regard to Algol variables. The connection, also, between the spectra of stars, their colour and their variation will no doubt be a future means of new discoveries.

But into these interesting questions we cannot go; nor, although we would fain do so, into the now celebrated meteoric theory of Mr. Lockyer, as an explanation of the phenomenon of stellar variation. Notwithstanding all Dr. Huggins has to say in favour of spectroscopic results the time has not yet come when one can build up a theory of the universe upon them.

But the search after new variables though most interesting and engrossing as far as the observer is concerned is not the most important section of variable star work. The systematic careful observation of known variables is, as far as the southern variables are concerned, a great desideratum.

The number of Cape circumpolar variables-or rather of variables south of $30^{\circ}$ south declination is 35 .

Twenty-one of these have been discovered by Dr. Gould while engaged on his great catalogue of the Southern Heavens. Six of these are invisible in ordinary binoculars. Five are visible all through their variations, four are visible at maximum but not at minimum, and twenty-one vary between the 6 th and 9 th magnitudes.

For the observation of known variables Argelander's method is perhaps the best. Call the variable star under examination " $a$ " and call two other stars in the neighbourhood of " $a$," one of which is slightly brighter than " $a$ " at max. and the other slightly less than " $a$ " at min., " $b$ " and " $c$." Consider the distance between " $b$ " and " $c$ " as 10-the absolute value of this "ten" can afterwards be obtained. Then the various ratios of $a$ to $b$ and $c$ can be thus set down:

$$
\begin{aligned}
& b-1 a-9 c \text { (From } b \text { to } a=1 \text { step : from } a \text { to } c=9 \text { steps) } \\
& \text { or } b-2 a-8 c \text { (From } b \text { to } a=2 \text { steps : from } a \text { to } c=8 \text { steps) } \\
& \text { or } b-3 a-7 c \text { (From } b \text { to } a=3 \text { steps : from } a \text { to } c=7 \text { steps) }
\end{aligned}
$$

always making the sum of the co-efficients (if we may so call them) $=10$. 
I send a fac-simile copy of the observations of known variablesand some suspected ones-on the evening of August 28th. It will explain the method of observation adopted here. The same plan is adopted night after night, and at the end of each month the values are copied into a journal. The ease with which a rough little chart can be made compared with the trouble of writing down the comparisons will be evident. The magnitudes are only relative, or at best a rough guess, but the relation between each star is as exact as possible.

I feel I have written enough, and I have the unpleasant consciousness that what I have written is not perhaps what would best stir up a more earnest and a more active interest in Practical astronomy. And perhaps the word of caution that I intend to finish my paper with will not be the most beneficial in that way.

Before long the observer will find his enthusiasm modified, and his confidence weakened by an unlooked-for result. He will not have taken down many sequences of stars before he will be bewildered by the number of variables he has come across. Half the number he has examined seem to vary. Now the observer can console himself with this fact, that this difficulty is because of the nature of the subject not because of the want of care on the part of the observer. No less an authority than Dr. Gculd assures us that every star is variable. These variations however are slight and generally erratic. The true variable will soon make its presence felt by regular and large variations, and when one has by real perseverance chanced upon a new variable he feels amply rewarded for all his trouble.

In observing variable stars also the same instrument should always be used. Different glasses as well as different eyes give different results. One peculiar lens will absorb more red rays than another, so that all red stars will be enfeebled by it.

At the commencement of this paper mention was made of star colours as a fruitful field of research. It is a fruitful field, for it embraces nearly the whole southern heavens. Also the charting down of the long lines and wisps, and streams, and curves of stars that make the sky such an ever-present delight even to gaze up at, affords a most interesting study.

Let any one run his eye along the Milky Way in the ueighbourhood of Circinus, Norma and Ara, and he will find an array of long majestic sweeps and whirls, of triangles and pentagons, all making up a marvel of artistic beauty. What stupendous grandeur is there, world linked to world, star to star, and universe to universe, and all 
to make God's firmament what it is, a thing of beauty and an exquisite type of the order and harmony of the Eternal.

\section{ADDENDUM.}

\section{Some of the Better Known Variables.}

R SCULPTORIS-R.A. $1^{\text {h }} 22^{\mathrm{m}}$ Dec. $-33^{\circ} 7^{\prime}, \max \cdot \operatorname{mag}=5.7, \min .=7 \cdot 7$. This star has a period of about seven months. At present it is visible to the naked eye, but it is rapidly decreasing. A minimum may be expected in November. It is well situated for observation. It is a very red star.

$\mathrm{L}_{2}$ Puppis-R.A. $7^{\mathrm{h}} 10^{\mathrm{m}}$ Dec. $-44^{\circ} 28^{\prime}, \max =3 \cdot 6$, min. $=6 \cdot 3$. This star has a period of 136 days and at present it is descending to a minimum, which it will reach about the beginning of November. It will then be more favourably situated for observation than it is now. It is one of a group of variable stars in this portion of the heavens. Next to the regions round $\theta$ Argus and $\theta$ Scorpii the portion of the sky in the neighbourhood of $\mathrm{L}_{2}$ Puppis is the most crowded in the Southern Heavens.

R Calrina-R.A. $9^{\mathrm{h}} 29^{\mathrm{m}}$ Dec. $-62^{\circ} 1^{\prime} \cdot \max ,=4 \cdot 3$, min. $9 \cdot 3$. The period of this celebrated variable is about 313 days, but it is no doubt variable. Special attention bas been given to it by Mr. Tebbutt, Windsor, N.S.W. It ceased to be visible in a 1 -in. glass on the 3 rd of June. Its nearness to the meridian prevented the obtaining of a minimum period. It is now increasing in brilliancy, and a maximum may be expected in January, 1892. The change in colour of this star has already been referred to.

$l$ CARIN $A-R . A .9^{\mathrm{h}} 42^{\mathrm{m}}$ Dec. $-61^{\circ} 57^{\prime}, \max$. 3·7, min. 5.2. Observations here give a period of $38 \pm 1$ days. Maxima were observed on April 23rd, May 29tb, and July 6th. All the variations are visible to the naked eye and are most interesting from the chain of stars that lie alongside it with which its variation may be easily compared.

A maximum of 3.5 was observed on April 23rd. 
As in the majority of variables the time of descent is twice greater than the time of ascent, There are also two very clearly murked halts in the descending light curve.

is Carine-R.A. $10^{\mathrm{h}} 6^{\mathrm{m}}$ Dec. $-60^{\circ} \quad 58^{\prime}, \quad \max .=6 \cdot 2, \quad \min .=9 \cdot 0$. Period seven months.

A maximum took place about the 20th June. At present it is almost invisible in a 1-in. glass, and because of its position most difficult to observe. At its maximum in June it was visible to the naked eye.

T CARIN 2 -R.A. $10^{\mathrm{h}} 51^{\mathrm{m}}$ Dec. $-59^{\circ} 56^{\prime}, \max \cdot 6 \cdot 2$, min. 6.y. Period undetermined, very probably $0 \cdot 7$ days. Observations here do not shew such a high maximum as $6 \cdot 2$, the greatest maximum yet observed being 6.5. Several of the stars in the vicinity of $\mathrm{T}$. Carinæ seem variable. This fact as well as the possible extreme shortness of its period should make it a favourite object for observers. An interval of three or four hours will serve to show its variation.

S. $6063, \mathrm{C}_{\mathrm{ARIN}} \mathrm{x}-\mathrm{R}$. A. $10^{\mathrm{h}} 53^{\mathrm{m}}$ Dec. $-59^{\circ} 9^{\prime}, \max .=6 \cdot 8, \min .=8 \cdot 2$. Period $=38 \pm 2$ days.

The period of increase is very rapid, five days being required to pass from min. to max. The light curve is a very interesting one. About twelve days after maximum the descent ceases for about five or six days. There is then a sudden fall to minimum. Maxima were observed on 18th July and 29th August. The period seems slightly irregular.

y Argus-R.A. $10^{\text {h }} 40^{\mathrm{m}}$ Dec. $-59^{\circ} 3^{\prime}, \max .7 \cdot 1$, min. $=7 \cdot 5$. This is the most remarkable variable known. In April 1843 Maclear found it equal in brilliance to Sirius. It had already, in 1822 , been noted by Burchell as equal to a Crucis. Loomis thinks a period of seventy years with subordinate maxima and minima the most satisfactory explanation of its erratic changes. Schönfeld however regards a regular period as very improbable. And this 
would seem the most satisfactory explanation, for in 1811 it was of the 4th Mag., while recent measurements by Mr. Finlay shew it to be of the 7th Mag. $\eta$ Argus is the central star of a nebula that has long been suspected of change. These surmisings bave received the most remarkable confirmation. A photograph of the Nebula taken at sydney quite recently shews that the portion which Herschel in 1837 deemed brightest has quite disappeared.

Future observation will no doubt prove that in this part of the Milky Way there is a region of the most stupendous change.

How stupendous even the change in $\eta$ Argus ismay be understood from the fact that it now shines with nearly two thousand times less light than it did in 1843.

R MuscaE-R.A. $12^{\mathrm{h}} 35^{\mathrm{m}}$ Dec. $-68^{\circ} 48^{\prime}, \max .=6 \cdot 6, \min .=7 \cdot 4$. Period 21 hours $21 \cdot 5$ mins.

This star will well repay observation as its rapid, though small, changes are most interesting. The maximum for any date can be calculated from the following elements where $t$ is the number of revolutions from the epoch :

$$
\text { Aug. } 26 \cdot 3+89 t \text {. }
$$

If the parallax of this star be less than $0 \cdot 1^{\prime \prime}$ what an astounding velocity of rotation-supposing this to be the cause of the regular variation-R. Muscæ must have !

$\kappa$ Pavonis-R.A. $18^{\mathrm{h}} 45^{\mathrm{m}}$ Dec. $67^{\circ}-22^{\prime}, \max .4 \cdot 0$, min. 5.1. The period of this star is $9 \cdot 1$ days and the light curve extremely regular.

Several maxima have been observed slightly greater than $4 \cdot 0 \mathrm{Mag}$.

The elements for minimum period are :

$$
\text { July } 10 \cdot 96 \pm \cdot 24+9 \cdot 1 t \text {, }
$$

And for maximum :

$$
\text { July } 6 \cdot 35 \pm \cdot 15+9 \cdot 1 t \text {. }
$$




\section{$2 \mathrm{BHL}$ Biodiversity Heritage Library}

Roberts, A W . 1890. "VARIABLE STAR OBSERVING AND RESULTS FROM OBSERVATIONS MADE AT LOVEDALE, SOUTH AFRICA." Transactions of the South African Philosophical Society 8, 24-32.

https://doi.org/10.1080/21560382.1890.9526290.

View This Item Online: https://www.biodiversitylibrary.org/item/113786

DOI: https://doi.org/10.1080/21560382.1890.9526290

Permalink: https://www.biodiversitylibrary.org/partpdf/175402

\section{Holding Institution}

Field Museum of Natural History Library

\section{Sponsored by}

The Field Museum's Africa Council

\section{Copyright \& Reuse}

Copyright Status: NOT_IN_COPYRIGHT

This document was created from content at the Biodiversity Heritage Library, the world's largest open access digital library for biodiversity literature and archives. Visit BHL at https://www.biodiversitylibrary.org. 